\title{
Sustentabilidade do desenvolvimento urbano de Campinas-SP: uma abordagem multicritério
}

\author{
Sustainability of the urban devevelopment of Campinas-SP: a multicriteria \\ approach
}

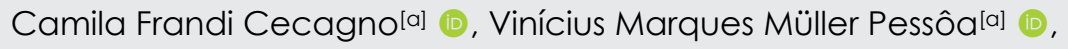
Danilo Mangaba de Camargo[b] (ㄱ), Mara Lúcia Marques[a,c] ()

\author{
[a] Pontifícia Universidade Católica de Campinas (PUC-Campinas), Faculdade de Arquitetura e Urbanismo, \\ Campinas, SP, Brasil \\ [b] Pontifícia Universidade Católica de Campinas (PUC-Campinas), Laboratório de Geoprocessamento, Campinas, \\ SP, Brasil \\ [c] Pontifícia Universidade Católica de Campinas (PUC-Campinas), Faculdade de Geografia, Centro de Ciências \\ Exatas, Ambientais e de Tecnologias, Campinas, SP, Brasil
}

Como citar: Cecagno, C. F., Pessôa, V. M. M., Camargo, D. M., \& Marques, M. L. (2020). Sustentabilidade do desenvolvimento urbano de Campinas-SP: uma abordagem multicritério. urbe. Revista Brasileira de Gestão Urbana, 12, e20190178. https://doi.org/10.1590/2175-3369.012.e20190178

\section{Resumo}

O objetivo consistiu na integração dos indicadores de sustentabilidade urbana pela abordagem multicritério de Programação por Compromisso (CP), a partir do modelo Pressão-Estado-Resposta, com vistas à avaliação do potencial de intervenção dos fatores socioeconômicos, ambientais e políticos no processo de urbanização. Essa abordagem foi aplicada na região norte-noroeste do município de Campinas-SP, empregando os componentes Pressão (uso do solo, expansão urbana e densidade populacional), Estado (áreas verdes, equipamentos urbanos e vulnerabilidade social) e Resposta (zoneamento de 2004 e zoneamento de 2018) para modelagem em SIG pelo método multicritério CP. Foi observado que $\sim 49 \%$ da área analisada apresentou bons indicativos de sustentabilidade, havendo redução de $\sim 29 \%$ com a implementação do plano de zoneamento de 2018. Provavelmente, a exclusão de zonas de conservação tenha sido o fator determinante dessa redução, conforme demonstram os indicadores de Pressão sobre a unidade de conservação Mata de Santa Genebra e o crescimento dendrítico nas áreas periurbanas. Porém, é preciso salientar que avaliação envolveu o estágio inicial do zoneamento de 2018, sendo prematura uma análise conclusiva sobre modificações do ambiente decorrentes do desenvolvimento. Assim, é recomendado que esse método de avaliação da sustentabilidade seja uma ferramenta permanente para análise das ações de planejamento e gestão do uso do solo urbano.

Palavras-chave: Desenvolvimento sustentável. Sistemas de informação geográfica. Tomada de decisões. Programação por compromisso. Planejamento urbano.

CFC é graduanda em Arquitetura e Urbanismo, e-mail: camilacecagno@hotmail.com VMMP é graduando em Arquitetura e Urbanismo, e-mail: vipessoa73@gmail.com

DMC é geográfo, mestre em Geociências e Meio Ambiente, técnico, e-mail: danilo.mangaba@gmail.com

MLM é geográfa, doutora em Geografia, professora, e-mail: mara.marques@puc-campinas.edu.br 


\section{Abstract}

The objective of the present work was to integrate the urban sustainability indicators by multicriteria approach using Commitment Programming (CP), which is based on Pressure-State-Response model, aiming to evaluate the intervention potential of socioeconomic, environmental and politics factors into the urbanization process. Such approach was applied to the north-northwest region of Campinas, SP, city by using Pressure (land use, urban growth and population density), State (green areas, urban equipment and social vulnerability) and Response (zoning plan 2004 and zoning plan 2018) components for modeling in GIS applying CP multicriteria method. It was observed that $49 \%$ of the analyzed area had a good indicative of sustainability, which was reduced till $29 \%$ with the implementation of the 2018 zoning plan. The exclusion of conservation areas is probably the determining factor for this reduction, as evidenced by pressure indicators on the Mata de Santa Genebra conservation unit and dendritic growth in the periurban areas. However, it should be noted that the evaluation encompassed the initial stage of zoning plan 2018, and a conclusive analysis of the environmental changes from the development was premature. Thus, it is recommended that this sustainability evaluation be a permanent tool to the analysis the actions of planning and management of urban land use.

Keywords: Sustainable development. Geographic information systems. Decision-making. Compromise programming. City planning.

\section{Introdução}

Com a intensificação da urbanização após a Revolução Industrial, é evidente e recorrente o aumento do consumo dos recursos naturais para suprir as demandas do aumento populacional contínuo (Acselrad, 2001). 0 processo desordenado de crescimento de uma cidade pode ser gerenciado para prezar a capacidade de resiliência que a natureza demanda, isto é, o ordenamento e o planejamento do território devem estar fundamentados nos princípios da sustentabilidade, promovendo um desenvolvimento inclusivo e equitativo (Gaspar, 1996; Martins \& Cândido, 2013).

0 termo sustentabilidade, conforme discussão fomentada no Fórum Mundial de Urbanização (Urban World Forum), realizado em 2002, relaciona a capacidade do ambiente de suportar as atividades antrópicas, considerando a análise de vulnerabilidade social, econômica e política (Braga et al., 2009). Assim, para analisar a sustentabilidade urbana, é preciso considerar a capacidade do processo de desenvolvimento em preservar os recursos naturais, a partir de ações que minimizam as desigualdades sociais, oferecendo boas condições de vida para a população residente e políticas públicas para solucionar problemas atuais e futuros (Braga et al., 2009; PNUD, 2011). Na abordagem da gestão sustentável de áreas urbanas, há prevalência da compreensão dos padrões espaço-temporais de urbanização, que, impulsionados pelos processos socioeconômicos, produzem efeitos sobre feições espaciais, como uso e ocupação do solo, sistema viário, áreas verdes e oferta de equipamentos urbanos (Mahiny \& Clarke, 2012).

A equidade na distribuição econômica é preponderante na durabilidade do processo de desenvolvimento urbano, sugerindo que a análise da durabilidade associada à distribuição do rendimento econômico constitui um aspecto padrão da resiliência evolutiva (Berg \& Ostry, 2017). Desse modo, a avaliação do processo de urbanização, a partir de indicadores de sustentabilidade, pode orientar as políticas que atuam sobre o território, com o intuito de viabilizar medidas mitigadoras de possíveis crises e preservar a qualidade de vida da população, diminuindo sua vulnerabilidade e aumentando a capacidade de adaptação (Wu, 2014). Um indicador descreve um estado ou uma resposta dos fenômenos que ocorrem nas dimensões ambientais, econômicas, socioeconômicas, culturais e institucionais (Franca, 2001). Os indicadores de sustentabilidade são utilizados para compreensão dos impactos das ações antrópicas nos ecossistemas, contribuindo para avaliação da sustentabilidade ao sintetizar as informações quantitativas e qualitativas (Kronemberger et al., 2008; Silva et al., 2010; Lopes \& Guerra, 2016; Marques, 2017). 
O estudo de sustentabilidade urbana por indicadores fundamenta-se no conceito que surgiu na década de 1980, propondo três vertentes de análise: (1) biocêntrica, composta de indicadores biológicos, físicoquímicos ou energéticos de equilíbrio ecológico de ecossistemas, que avaliam a situação física e/ou biológica dos sistemas naturais; (2) econômica, composta do capital natural e do uso de recursos naturais, relacionando os aspectos naturais e econômicos com a qualidade de vida humana; (3) qualidade ambiental, vertente que pondera os critérios de estado, pressão e resposta, combinando aspectos do ecossistema natural, do sistema econômico e da qualidade de vida (Herculano et al., 2000; Braga et al., 2009; Santos, 2015).

Dessa forma, o presente estudo adotou a terceira vertente como abordagem de referência, empregando o modelo Pressão-Estado-Resposta (PER) para a estruturação da avaliação da sustentabilidade pelo método multicritério de Programação por Compromisso (CP), tendo por objetivo propor uma forma de análise da sustentabilidade urbana da região norte-noroeste do município de Campinas-SP.

O município de Campinas foi objeto dessa proposta por ter experenciado um período de rápida expansão urbana decorrente do movimento de migração da Região Metropolitana de São Paulo, desde o processo de desconcentração industrial, em 1970, que contribuiu para metropolização de Campinas (Baeninger, 2001).

\section{Fundamentos de avaliação de sustentabilidade urbana}

O modelo PER procura analisar a relação entre a atividade humana e o ambiente, constituindo uma abordagem para selecionar e mensurar indicadores que permitam avaliar a sustentabilidade do ambiente urbano. Esse modelo foi desenvolvido pela Organização para a Cooperação e o Desenvolvimento Econômico (OCDE) e fundamenta-se no conceito de que as ações antrópicas exercem pressão sobre o ambiente, "alterando a qualidade e a quantidade de recursos naturais, ou seja, alterando o seu estado, e a sociedade responde a essas mudanças mediante políticas ambientais, econômicas ou setoriais" (OCDE, 1993). Segundo essa organização, o modelo PER apresenta como vantagem a possibilidade de evidenciar a associação entre atividade humana e ambiente, bem como facilitar o diagnóstico de problemas e indicar meios para elaboração de políticas públicas. Nesse modelo, os indicadores se dividem em três categorias: indicadores da pressão ambiental, indicadores das condições ambientais ou de estado e indicadores de respostas sociais. 0 componente Pressão é constituído pelas forças econômicas e sociais, tais como ocupação territorial e consequente uso do solo urbano, crescimento e distribuição da população e distribuição das atividades econômicas e seu impacto na estrutura de ocupação do espaço. 0 componente Estado indica as alterações do ambiente em resposta às diferentes pressões antrópicas. Por último, as ações que diminuem e evitam os impactos negativos ao ambiente correspondem ao componente Resposta, analisando a atuação de instrumentos de indução/regulação do desenvolvimento urbano, como planos diretores e leis de parcelamento do solo, zoneamento econômico e ecológico e áreas de proteção ambiental vigentes (Sepe \& Braga, 2009).

No entanto, esse método apresenta fragilidades por: (a) não considerar as ações da natureza como um indicador de pressão, mas apenas as antrópicas, visto que ações naturais também podem modificar o ambiente; (b) simplificar situações complexas, induzindo uma relação de causalidade linear; (c) não estabelecer metas de sustentabilidade; e (d) apresentar dificuldade na obtenção de dados oficiais referentes às políticas públicas, analisando apenas planos e medidas já implementadas, como planos diretores, leis de parcelamento do solo e zoneamento urbano. Por causa dessas limitações, a comissão de desenvolvimento sustentável da ONU, em 1999, abandonou o modelo PER (Kemerich et al., 2014).

Porém, atualmente com a regulamentação que viabiliza o acesso à informação pública, a limitação de obtenção de dados oficiais foi minimizada. Também, com o intuito de suprir as limitações do modelo, são empregados métodos e técnicas de análise espacial em Sistema de Informação Geográfica (SIG) para o estudo da sustentabilidade, utilizando indicadores físicos e antrópicos e considerando a materialização 
das ações implementadas pelas políticas públicas. A análise espacial em SIG proporciona uma ampla variedade de aplicações em estudos urbanos, tais como mapeamento e monitoramento do ambiente urbano pelas análises do uso e cobertura do solo, da morfologia e das estruturas urbanas, análise da distribuição dos aspectos socioeconômicos, bem como implementação de modelos de avaliação da realidade e de predição de cenários (Batty, 2002). Dessa maneira, o emprego do SIG em planejamento urbano permite melhorar a qualidade da análise de dados quantitativos e qualitativos, agregando informações e conhecimento para o processo decisório, contribuindo, assim, para o gerenciamento do desenvolvimento sustentável das cidades.

De acordo com Van Maarseveen et al. (2019), não há uma definição comum para cidade sustentável, mas há consenso sobre o desenvolvimento urbano sustentável que ocorre quando as necessidades do presente são atendidas sem prejudicar as necessidades de futuras gerações. Além disso, a cidade sustentável garante a capacidade de resiliência a partir de projetos de avaliação da realidade, de planejamento e de ações que visam a uma melhor qualidade de vida e minimizam a vulnerabilidade social dos habitantes (Figura 1). A capacidade de resiliência e a vulnerabilidade são decorrentes do próprio processo de urbanização e são observadas nas organizações sociais, econômicas e morfológicas resultantes, sempre analisadas em uma escala temporal (Chelleri, 2012).

$\mathrm{Na}$ avaliação da sustentabilidade, diversos indicadores qualitativos e quantitativos podem ser relacionados e/ou integrados com o emprego de método multicritério, o qual possibilita a análise conjunta dos indicadores da problemática de estudo e avalia alternativas para proposição de um cenário ideal (Köksalan et al., 2013; Wang et al., 2016). A adoção do método multicritério flexibiliza a opção da amostragem de variáveis necessárias para análise de problemáticas. Segundo Gobbetti \& Braba (1997), o método multicritério de $\mathrm{CP}$ se enquadra nos métodos que admitem mais de uma função objeto, utilizando a articulação progressiva das preferências e permitindo modificar a relação dos indicadores caso a solução não seja satisfatória.

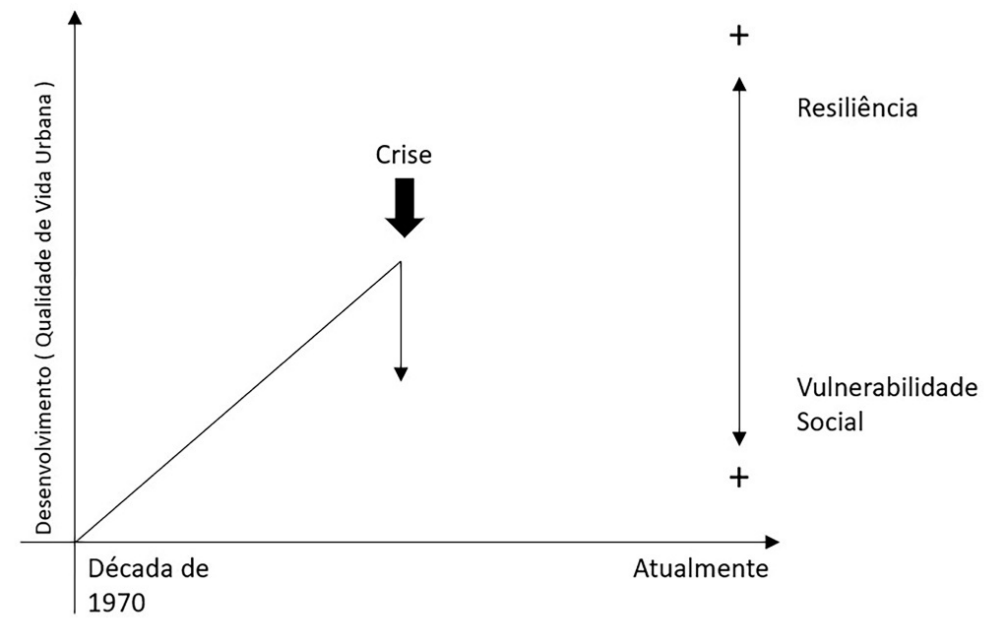

Figura 1 - Trajeto de desenvolvimento sustentável em um período de análise. Fonte: European Commission (PNUD, 2011).

O método CP propõe a identificação da distância métrica entre dois pontos com coordenadas conhecidas, com base no conceito geométrico do melhor ponto ou "ponto ideal". Na avaliação da sustentabilidade, o "ponto ideal" representa o máximo de desenvolvimento com o mínimo impacto ambiental (Zeleny \& Cochrane, 1982). Pela dificuldade de se obter o chamado "ponto ideal", é adotado um "ponto meta" que seja menor ou igual ao "ponto ideal", como demonstrado na Figura 2 (Gershon \& Duckstein, 1983; Zuffo et al., 2002). 


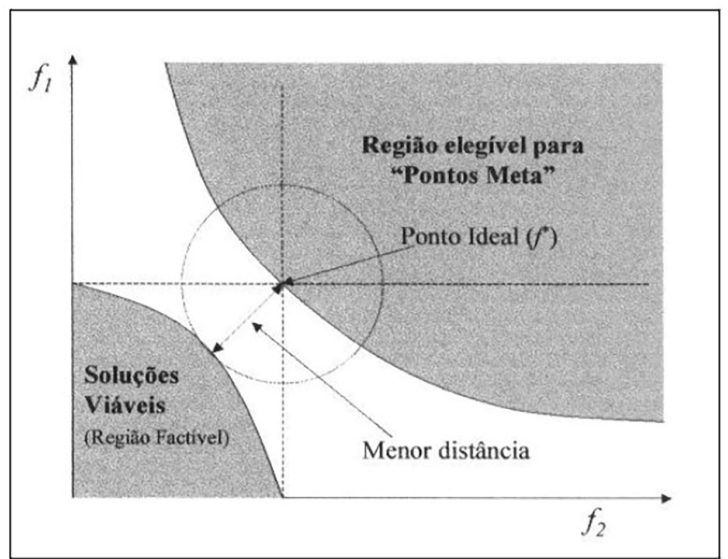

Figura 2 - Relação do "ponto ideal" e do "ponto meta". Fonte: Gershon \& Duckstein (1983 apud Zuffo et al., 2002).

O método CP possui facilidade de implementação em ambiente SIG, pois inicialmente analisa o conjunto de alternativas, ou seja, todas as células das matrizes (ou planos de informação) inclusas no banco de dados geográficos (BDG), avaliando-as de forma que cada célula é considerada um sítio, composto de $n$ atributos, para análise espacial local (Berry, 1964). Para cada alternativa correspondente aos critérios adotados, que são os planos de informação componentes do BDG, é atribuído um peso. Cada peso pode ser definido por uma estrutura de decisão ou de forma subjetiva. Posteriormente esses pesos são normalizados em uma escala de 0 a 1, conforme demostrado na Equação 1.

$x^{k}=\left(x_{1}^{k}, x_{2}^{k}, \ldots, x_{3}^{k}\right)$

sendo: k valores de $1, \ldots, K ; x_{i}^{k}$ o score de um atributo $i$ para cada alternativa $k$; e $x^{k}$ o vetor dos números $K$ assinalados para cada alternativa, sintetizando toda a informação ao considerar a totalidade dos critérios. Por ser $i$ compreendido como cada critério avaliado, então o conjunto $i$ produz um vetor com $k$ números, avaliando os níveis alcançados pelo atributo $i$. Por último, são avaliadas todas as alternativas disponíveis com base em sua distância multidimensional em relação ao ponto ideal (ou ponto meta), de acordo com a Equação 2 (Zuffo et al., 2002).

$l_{s}(x)=\left[\sum_{i=1}^{n} \alpha_{i}^{s}\left|\frac{f_{i}^{*}-f_{i}(x)}{f_{i}^{*}-f_{i, w}}\right|^{s}\right]^{1 / s}$

sendo: $l_{s}$ a distância do valor da solução ideal; $\alpha_{i}$ os pesos atribuídos de forma subjetiva ou por processos de atribuições de preferências; $f^{*}{ }_{i}$ o melhor valor obtido para o critério $i ; f_{\mathrm{i}, \mathrm{w}}$ o pior valor obtido para o

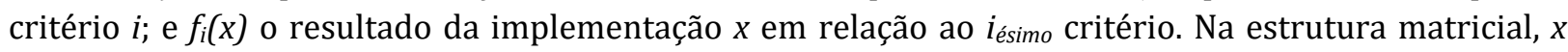
corresponde ao valor associado a cada pixel de cada plano de informação contido no banco de dados geográficos (BDG); e $s$ reflete a importância que o tomador de decisão atribui aos desvios máximos. Contudo, em estudos que buscam comparar o método CP a outros métodos, é adotado esse valor como sendo igual a 1 (um) (Zuffo et al., 2002). Portanto, quando $s$ assume o valor 1, a Equação 2 pode ser simplificada conforme a Equação 3.

$l_{s}(x)=\sum_{i=1}^{n} \alpha_{i}\left|\frac{f_{i}^{*}-f_{i}(x)}{f_{i}^{*}-f_{i, w}}\right|$

sendo: $l_{s}$ a distância do valor ideal; $\alpha_{i}$ o peso atribuído a cada componente; $f_{i}^{*}$ o melhor valor para o

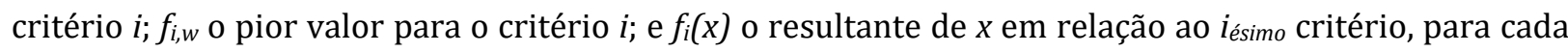
célula da matriz. 


\section{Procedimentos metodológicos}

O modelo PER e o método de CP foram empregados na estruturação da avaliação do desenvolvimento urbano como forma de analisar a sustentabilidade do desenvolvimento de acordo com a proposta de PNUMA (2017), empregando o sistema de informação geográfica ArcGIS - ESRI (2015).

\section{Contextualização da área de estudo}

Neste estudo, foi definido como recorte espacial da área de pesquisa o trecho que abrange o centro norte-noroeste do município de Campinas (Figura 3). A área possui declividade predominante entre $3 \mathrm{e}$ $8 \%$, com áreas de colinas que apresentam altimetria entre 709 e 769 m. A região é banhada por vários corpos d'água, com destaque para o Ribeirão Anhumas, afluente da margem esquerda do Rio Atibaia. Em alguns pontos, são encontrados áreas verdes preservadas, parques e bosques, com a presença do Parque Portugal - Lagoa Taquaral (Figura 4).

Na elaboração dos mapas de declividade, hipsometria e visualização do relevo, foi utilizado o Modelo Digital de Elevação (MDE), disponibilizado pelo projeto Topodata, a partir dos dados do sistema SRTM (Shutler Radar Topografhic of Mission) (Valeriano \& Rossetti, 2012). 0 plano de informação da rede hidrográfica foi obtido no site da Agência Nacional das Águas (ANA, 2018), na escala 1:50.000.

O mapa da rede viária foi adquirido na base de dados disponível do OpenStreetView (2015). Em relação aos fluxos viários, as principais rodovias são: Anhanguera (SP-330), Dom Pedro I (SP-065), Professor Zeferino Vaz (SP-332) e Governador Doutor Adhemar Pereira de Barros (SP-340). De acordo com os dados do censo demográfico de 2010 (IBGE, 2011), na área de estudo há uma população de 232.035 habitantes, apresentado uma baixa densidade de ocupação, com rendimento médio variando entre 1 e 27 salários mínimos (Figura 5).
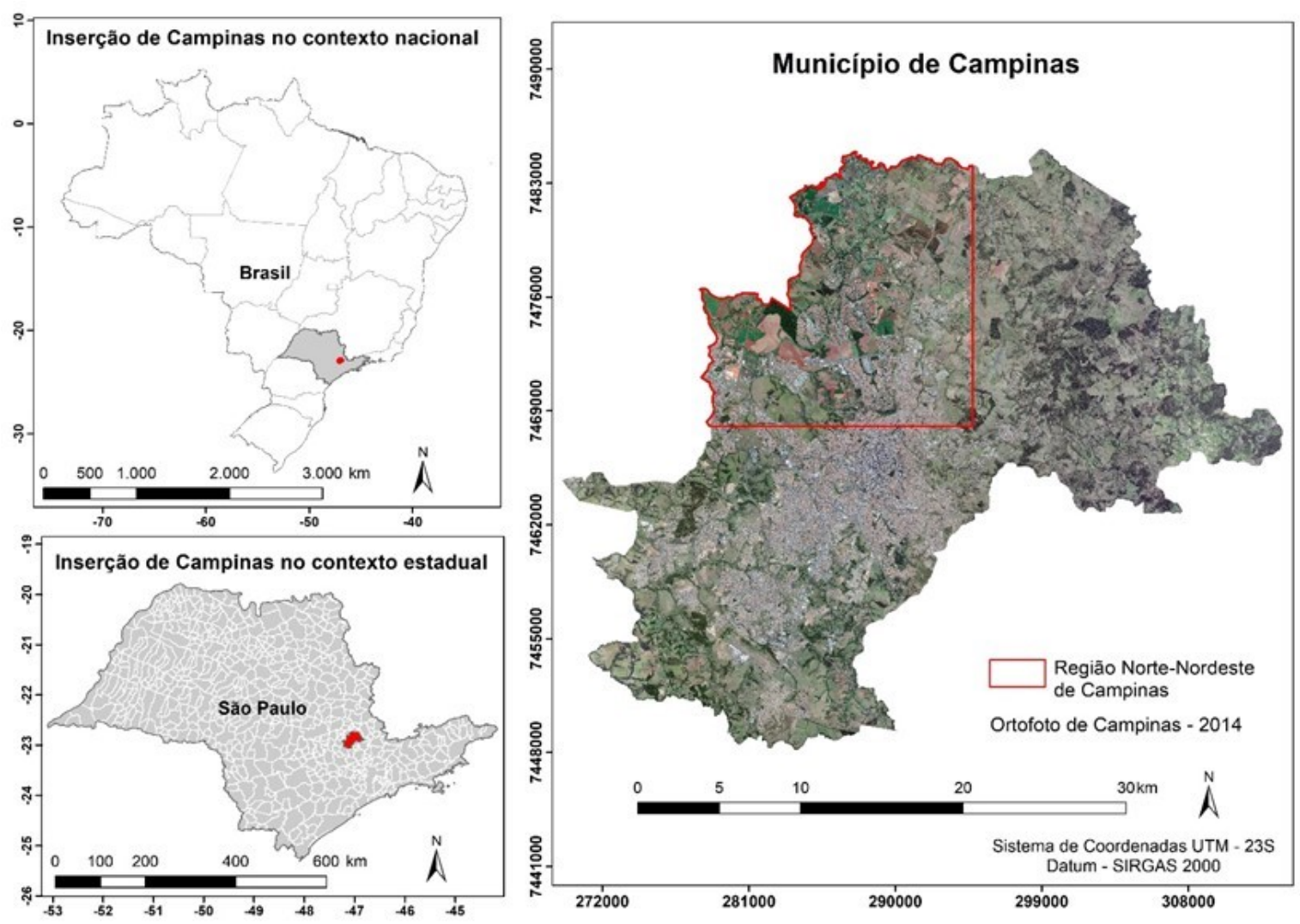

Figura 3 - Inserção da área de estudo no município de Campinas-SP, no estado de São Paulo e no Brasil. Fonte: adaptada de IBGE (2015) e ortofoto do município de Campinas (2014). 

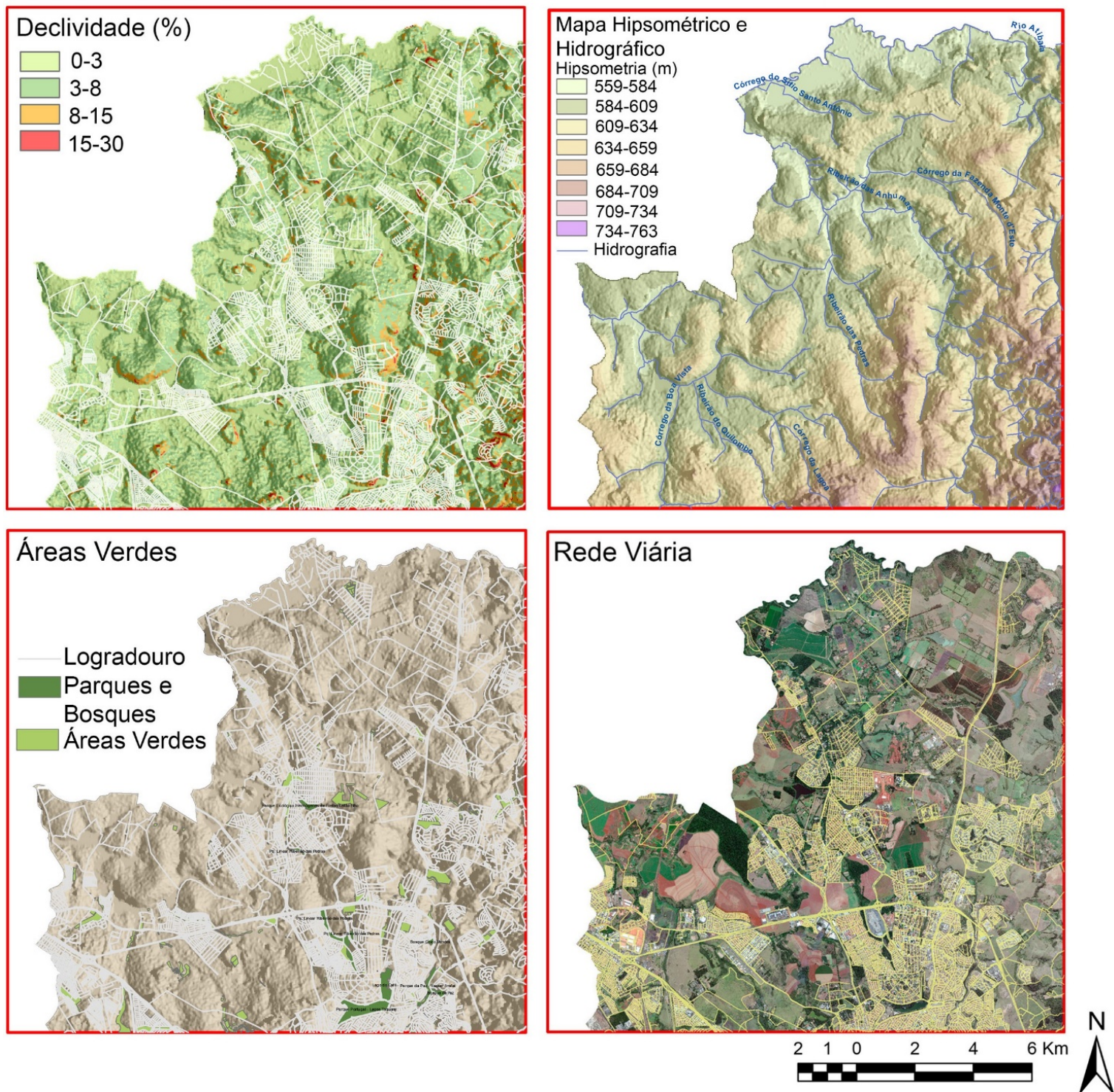

Figura 4 - Contextualização da área de estudo pelos mapas de declividade, hipsometria, hidrografia, logradouros, áreas verdes e rede viária. Fonte: adaptada de ANA (2018), Shutler Radar Topografhic of Mission, Valeriano \& Rossetti (2012), OpenStreetView (2015), ortofoto do município de Campinas (2014) e IBGE (2015).
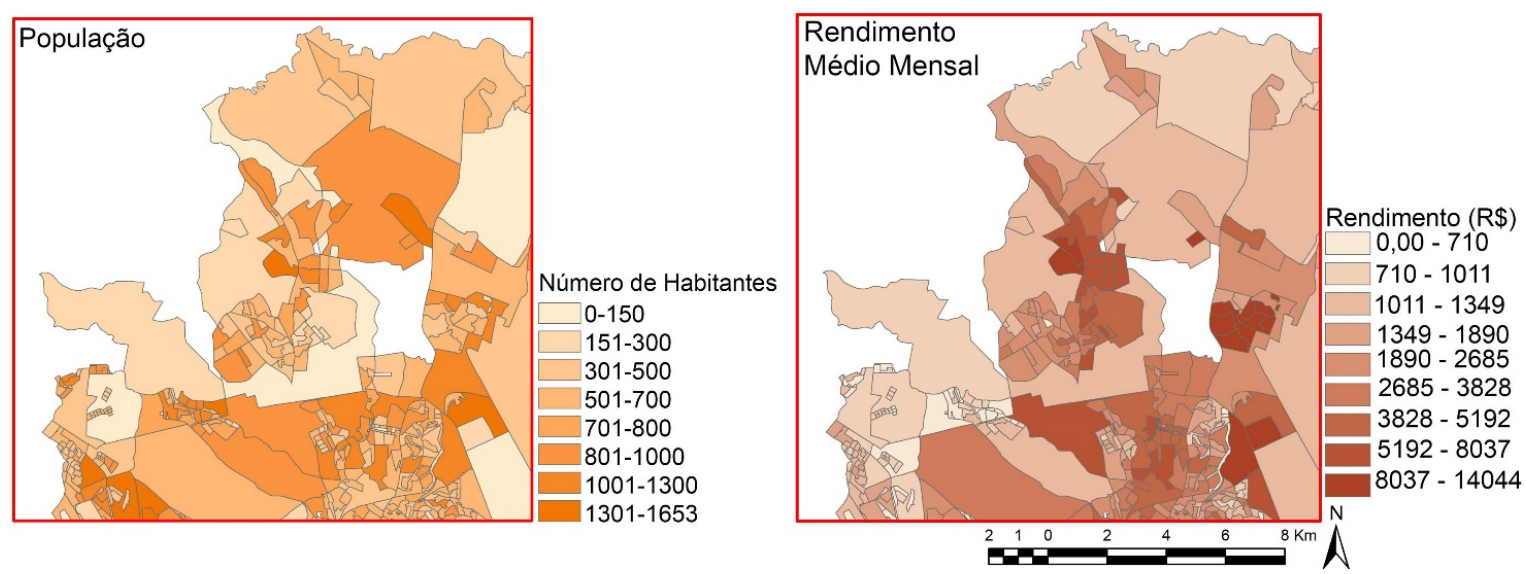

Figura 5 - Contextualização da área de estudo pelos mapas de população e rendimento médio por responsável por setor censitário. Fonte: IBGE (2011). 


\section{Componente Pressão: contexto socioeconômico e uso e ocupação do solo}

O componente Pressão (C1) foi analisado pelo contexto de ocupação territorial e uso do solo, expansão urbana do período de 1975 a 2018 e densidade demográfica. Dessa forma, C1 avaliou a distribuição das atividades econômicas e seu impacto na estrutura de ocupação do solo urbano e o crescimento e distribuição da população.

O mapeamento da densidade populacional foi obtido pelo levantamento do censo demográfico de 2010, constituindo o indicador de distribuição demográfica.

O mapeamento do uso e ocupação do solo de 2018 e a delimitação da mancha urbana de 1975 e 2018 foram realizados a partir da classificação digital da imagem orbital do sistema LANDSAT, sensores MSS (Multispectral Scanner) e OLI (Operational Land Imager), em 27/05/1975 e 08/08/2018. Foram realizados os processamentos de realce de imagens e georreferenciamento. Em seguida, o método de classificação por região foi utilizado para o mapeamento das classes de cobertura do solo de 2018: vegetação arbórea, vegetação rasteira, solo preparado para cultivo, solo exposto, cobertura cerâmica, cobertura de concreto, cobertura de alumínio, cobertura asfáltica e água. Na imagem de 1975, foi realizada apenas a classificação como: urbano e não urbano. Em ambas as datas, as imagens foram, inicialmente, segmentadas em áreas homogêneas definidas pelos limiares de área, textura, média e variância dos valores de reflectância espectral, atribuindo-se valores para os seguintes parâmetros: similaridade 20; área 2; tamanho 1. Nas imagens segmentadas, foram identificadas amostras de treinamento representativas de cada classe e, posteriormente, realizadas as classificações em função dos atributos espectrais (tonalidade e média) e espaciais (compacidade e forma) (Meneses \& Almeida, 2012). Os resultados das classificações foram validados pela análise da matriz de confusão e índice Kappa, a partir de 1.000 amostras de referência para cada classe, por método aleatório estratificado (Congalton \& Green, 2009).

O mapa de cobertura do solo (2018) foi corrigido visualmente e reclassificado em classes de uso e cobertura do solo, e cada classe de uso foi ponderada pelos critérios: capacidade de infiltração, área construída, perda de solo e cena (refúgio urbano). Foram realizadas observações de campo complementares para comprovação de ocupações irregulares (moradias subnormais), seguindo o critério descrito em IBGE (2011).

\section{Componente Estado: análise dos recursos do ambiente urbano}

O mapa síntese do componente Estado (C2) do ambiente urbano foi elaborado pelas informações sobre vulnerabilidade social, equipamentos urbanos e áreas verdes. Os dados referentes aos equipamentos urbanos (educação, cultura e lazer) e áreas verdes foram obtidos na Prefeitura Municipal de Campinas (Campinas, 2018).

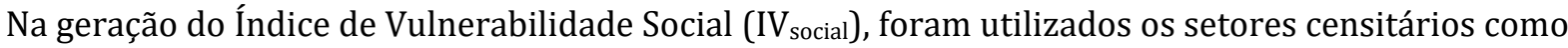
unidade de mapeamento. Foram extraídos oito parâmetros do censo demográfico de 2010 (IBGE, 2011) para gerar seis indicadores que foram escalonados em índice de 0 a 1 e normalizadas pelo Índice de Desenvolvimento Humano Municipal de Campinas, conforme a Equação 4 (Goerl et al., 2012; Fritzsche et al., 2014; Marques et al., 2018).

$$
I V_{\text {social }}=\frac{D_{d}+N_{m}+M_{m}+T x_{D E P}+T x_{E}+T x R_{\text {carente }}}{I D H M}
$$

sendo: $D_{d}$ a densidade demográfica; $N_{m}$ o número de moradores no setor censitário; $M_{m}$ a média de moradores por domicílio; $T x_{D E P}$ a taxa de população $\geq 65$ anos e $<12$ anos; $T x_{E}$ a taxa de pessoas analfabetas acima de 12 anos; $T x R_{\text {carente }}$ a taxa de responsáveis sem salário ou com até 1 salário mínimo; e o IDHM=0,805 (PNUD, 2013).

\section{Componente Resposta: políticas públicas e instrumentos reguladores}

O componente Resposta, referente às políticas públicas e instrumentos reguladores utilizados na gestão do território urbano, foi analisado pela identificação e levantamento dos mapas relacionados à 
implementação da Lei de Zoneamento de Uso e Ocupação do Solo (Lei no 6031/1988). Na composição desse componente, foi utilizado o mapeamento do zoneamento de 2004 (Lei no 12.195/2004) vigente até 2018, como também o mapeamento do zoneamento proposto no final de 2018 (Lei Complementar no 208, de 20 de dezembro de 2018) (Campinas, 2018).

\section{Avaliação da sustentabilidade pelo método Programação por Compromisso}

As variáveis de cada indicador dos componentes do modelo PER foram padronizadas em oito escalas nominais, de acordo com sua relevância para a sustentabilidade (S), estabelecendo os níveis: S1 - péssimo; S2 - ruim; S3 - insatisfatório; S4 - regular; S5 - aceitável; S6 - satisfatório; S7 - bom; S8 - ótimo. Os valores atribuídos aos níveis seguiram uma escala de transformação linear (Equação 5), conforme empregado por Nguyen et al. (2015) para o estudo da sustentabilidade do uso do solo.

$x_{i j}^{\prime}=\frac{x_{i j}}{x_{j}^{\max }}$

sendo: $x_{i j}$ o valor de relevância; e $x_{j}^{\max }$ a máxima relevância atribuída. Essa transformação linear ponderou as variáveis entre 0,125 e 1,000. Uma vez que os indicadores não apresentaram influência nula e/ou restrição sobre a sustentabilidade, não foi empregado o valor zero.

Os indicadores do componente Pressão (C1) e do componente Estado (C2) foram integrados pelo método CP, empregando as Equações 6 e 7. Para a atribuição dos pesos em $\mathrm{C} 1$ e C2, foi utilizada a proposta de Bana Costa (2005), considerando valores de relevância de sustentabilidade entre 1 e 7 para os indicadores M1, M2 e M3 (mapas critério) de cada componente, pela escala de importância (I): I7 - extrema; I6 - muito forte; I5 - forte; I4 - moderada; I3 - fraca; I2 -muito fraca; e I1 - nula.

O componente Pressão (C1) foi obtido pela Equação 6.

$$
l_{s}(x)_{C l}=\left(0,31\left|\frac{0,75-M 1}{0,75-0.25}\right|\right)+\left(0,44\left|\frac{0,375-M 2}{0,375-0,125}\right|\right)+\left(0,25\left|\frac{0,875-M 3}{0,875-0,25}\right|\right)
$$

sendo: Is a distância do ponto ideal; 0,31 o peso atribuído ao uso do solo (M1); 0,75 o melhor valor obtido para esse critério; 0,25 o pior valor obtido; 0,44 o peso atribuído à expansão urbana (M2); 0,375 o melhor valor obtido para esse critério; 0,125 o pior valor obtido; 0,25 o peso atribuído à densidade populacional (M3); 0,875 o melhor valor obtido para esse critério; e 0,25 o pior valor obtido.

0 componente Estado (C2) foi obtido segundo a Equação 7.

$$
l_{s}(x)_{C 2}=\left(0,37\left|\frac{0,875-M 1}{0,875-0,125}\right|\right)+\left(0,44\left|\frac{0,75-M 2}{0,75-0,125}\right|\right)+\left(0,19\left|\frac{0,75-M 3}{0,75-0,125}\right|\right)
$$

sendo: Is a distância do ponto ideal; 0,37 o peso atribuído a áreas verdes (M1); 0,875 o melhor valor obtido para esse critério; 0,125 o pior valor obtido; 0,44 o peso atribuído a equipamentos urbanos (M2); 0,75 o melhor valor obtido para esse critério; 0,125 o pior valor obtido; 0,19 o peso atribuído à vulnerabilidade social (M3); 0,75 o melhor valor obtido para esse critério; e 0,125 o pior valor obtido.

O componente Resposta foi elaborado para o zoneamento de 2004 (C3 $\left.\mathrm{Z}_{\mathrm{Z} 2004}\right)$ e o zoneamento de 2018 (C3 ${ }_{\mathrm{Z} 2018)}$ e, juntamente com os componentes Pressão (C1) e Estado (C2), foi integrado pelo método CP para avaliar a sustentabilidade do zoneamento do solo urbano de 2004 e 2018, respectivamente, pelas Equações 8 e 9, cujos critérios também foram ponderados pela proposta de Bana Costa (2005).

A avaliação da sustentabilidade pela integração dos componentes Pressão (C1), Estado (C2) e Resposta (C322004) foi determinada pela Equação 8.

$$
l_{s}(x)_{Z 2004}=\left(0,33\left|\frac{0,875-C 1}{0,875-0,25}\right|\right)+\left(0,40\left|\frac{0,875-C 2}{0,875-0,25}\right|\right)+\left(0,27\left|\frac{1-C 3}{1-0,25}\right|\right)
$$


sendo: $I s$ a distância do ponto ideal; 0,33 o peso atribuído ao componente $\mathrm{C} 1 ; 0,875$ o melhor valor obtido para esse critério; 0,25 o pior valor obtido; 0,40 o peso atribuído ao componente $\mathrm{C} 2 ; 0,875$ o melhor valor obtido para esse critério; 0,25 o pior valor obtido; 0,27 o peso atribuído ao zoneamento de 2004 (C3); 1 o melhor valor obtido para esse critério; e 0,25 o pior valor obtido.

Para obter a avaliação da sustentabilidade pelo zoneamento de 2018, os componentes Pressão (C1), Estado (C2) e Resposta ( ${ }^{2} 3_{\mathrm{Z} 2018}$ ) foram integrados pela Equação 9.

$$
l_{s}(x)_{Z 2018}=\left(0,33\left|\frac{0,875-C 1}{0,875-0,25}\right|\right)+\left(0,40\left|\frac{0,875-C 2}{0,875-0,25}\right|\right)+\left(0,27\left|\frac{0,625-C 3}{0,625-0,25}\right|\right)
$$

sendo: Is a distância do ponto ideal; 0,33 o peso atribuído ao componente $\mathrm{C} 1 ; 0,875$ o melhor valor obtido para esse critério; 0,25 o pior valor obtido; 0,40 o peso atribuído ao componente $\mathrm{C} 2 ; 0,875$ o melhor valor obtido para esse critério; 0,25 o pior valor obtido; 0,27 o peso atribuído ao zoneamento de 2018 (C3); 5 o melhor valor obtido para esse critério; e 0,25 o pior valor obtido.

Após a aplicação do modelo PER, os valores resultantes foram classificados pelo método quantil para fornecer quatro níveis de sustentabilidade do desenvolvimento urbano: ótimo $(\geq 0,7)$, $\operatorname{bom}(\geq 0,4 \mathrm{e}<0,7)$, razoável $(\geq 0,2$ e $<0,4)$ e ruim $(<0,2)$.

\section{Resultados e discussão}

Em relação aos indicadores do componente Pressão (Figura 6), foi verificado que o mapeamento do uso e ocupação do solo, gerado pela classificação digital, obteve um índice de acerto geral de 90,2\%, com coeficiente Kappa de 0,89, sendo esses valores demonstrativos da forte concordância espacial decorrente da classificação. Foi observada uma expansão da área urbana, que ocupava $6,91 \mathrm{~km}^{2}$ (3,24\%) da área total de 283,41 $\mathrm{km}^{2}$ em 1975, passando a ocupar 49,82 $\mathrm{km}^{2}$ (23,36\%) em 2018.
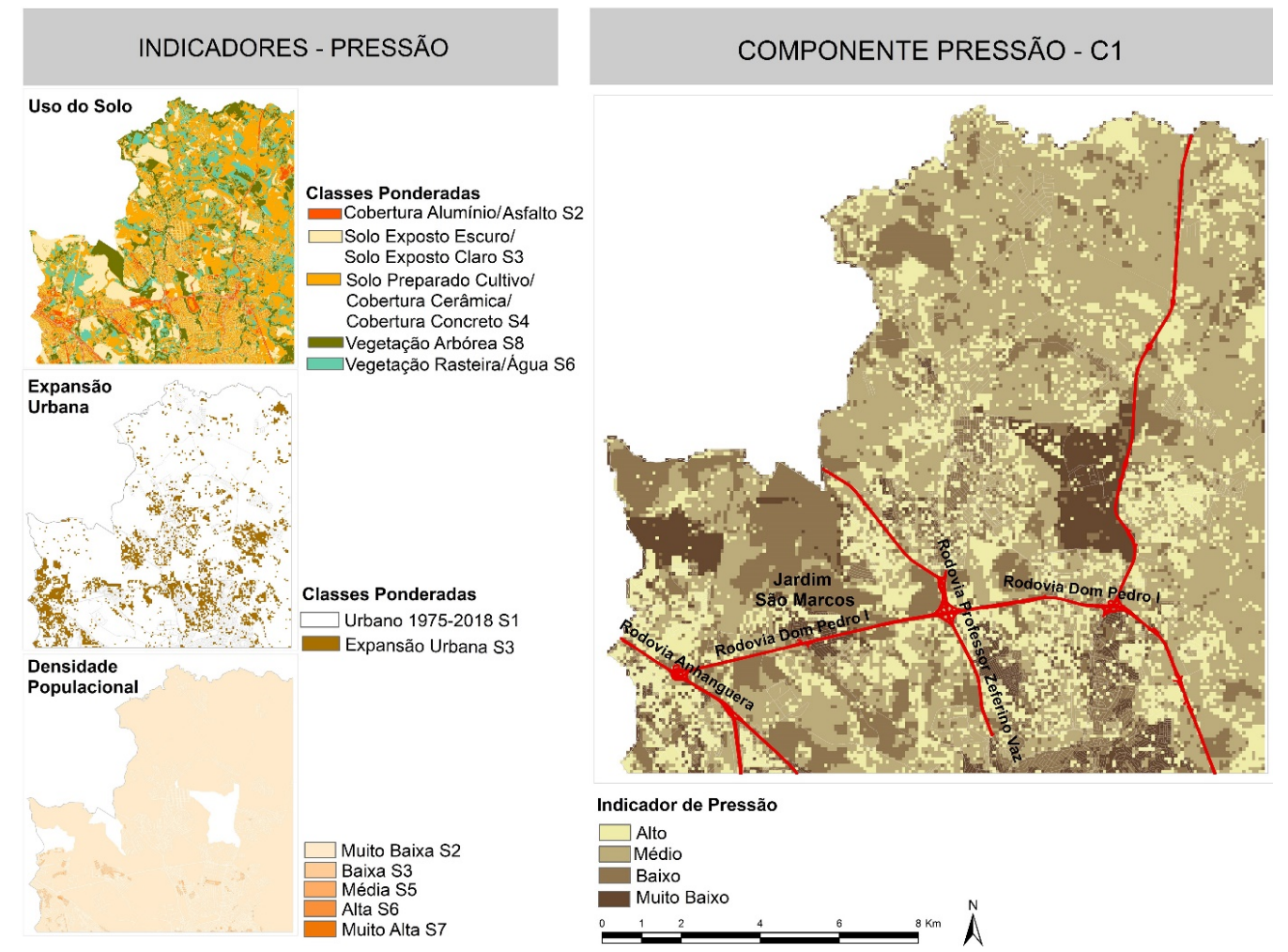

Figura 6 - Indicadores de Pressão (painéis: uso do solo, expansão urbana e densidade populacional) e componente Pressão resultante (C1). Fonte: Elaborada pelos autores. 
Em decorrência do desenvolvimento da área urbanizada, ocorreu a consequente redução da área rural e da cobertura vegetal. Apesar da expansão urbana, não houve concomitante aumento da densidade populacional, notando que a pressão desse indicador está circunscrita às áreas de entorno dos principais eixos viários, como as Rodovias Dom Pedro I, Anhanguera e Prof. Zeferino Vaz. Nessa área também foram identificadas ocupações irregulares, predominantemente no bairro Jardim São Marcos. Portanto, analisando o componente Pressão (C1), é possível destacar áreas mais expostas às pressões oriundas das ações antrópicas no entorno dos eixos estruturadores, bem como áreas que representam reservas naturais e uso rural dentro das áreas urbanizadas e/ou próximas a elas, por causa do crescimento dendrítico nessas áreas periurbanas. Esse é o caso marcante da área do entorno da Mata Santa Genebra, unidade de conservação federal que possui $2,52 \mathrm{~km}^{2}$ e constitui um refúgio ecológico de mais de 300 espécies animais e 600 espécies vegetais.

Quanto ao componente Estado (C2) (Figura 7), cujos indicadores foram áreas verdes urbanas, equipamentos urbanos e vulnerabilidade social, foi notada a presença de poucos fragmentos de vegetação, com dimensão reduzida, desconectados entre si e dispersos pela área analisada. A distribuição dos equipamentos urbanos contribuiu para a identificação e quantificação dos tipos de serviços de cultura, lazer e educação encontrados na área. Foi verificado que a maior concentração desses equipamentos está na área sul e leste da Rodovia Dom Pedro I, por se tratar de uma região com ocupação urbana mais consolidada. Porém, ao norte dessa rodovia, há também a presença de instituições de ensino, como a Pontifícia Universidade Católica de Campinas (PUC-Campinas) e a Universidade Estadual de Campinas (UNICAMP), que se configuraram em importantes atrativos para a urbanização.
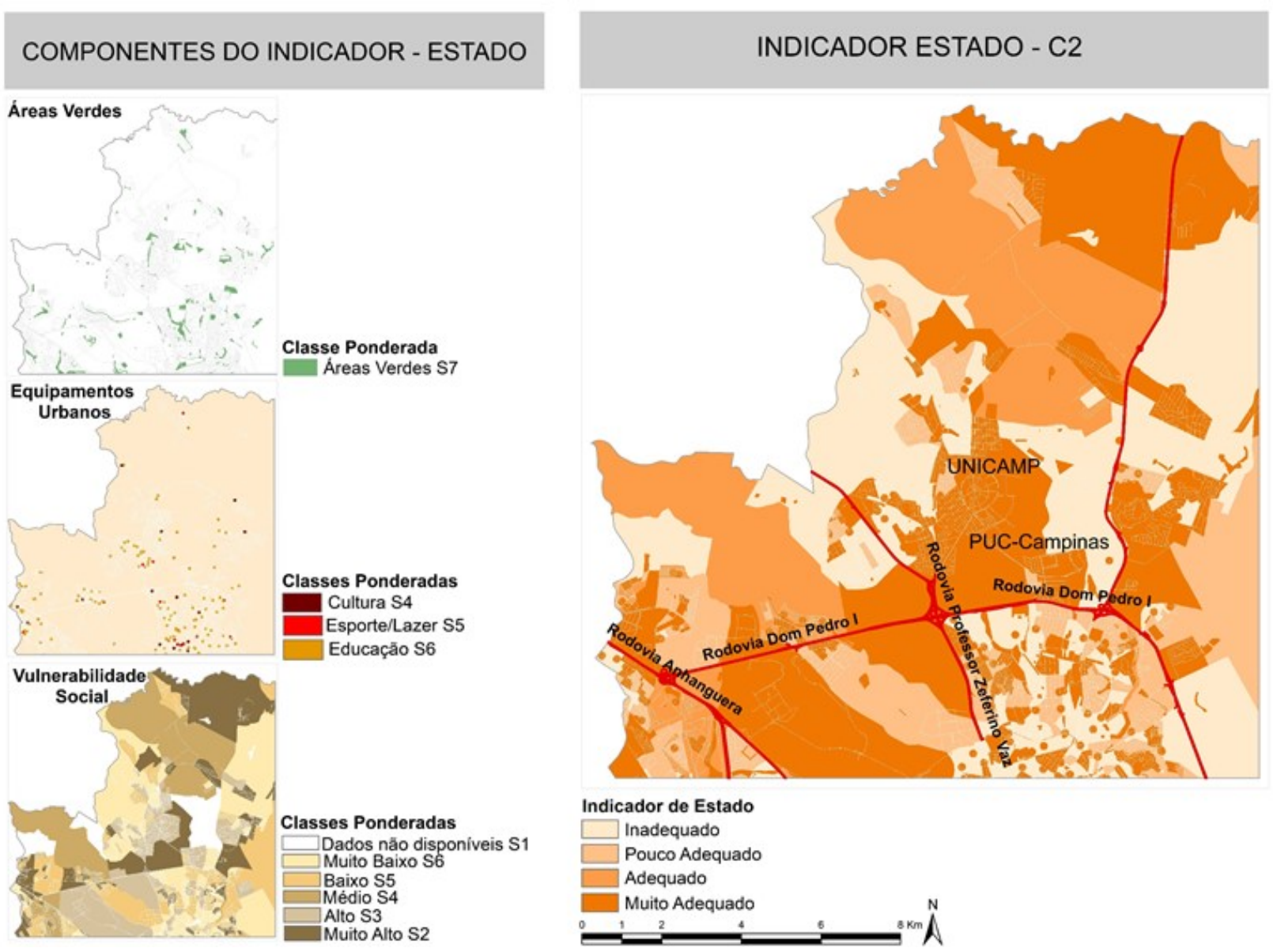

Figura 7 - Indicadores de Estado (painéis: áreas verdes, equipamentos urbanos e vulnerabilidade social) e componente Estado (C2). Fonte: Elaborada pelos autores. 
O mapa de vulnerabilidade social destacou zonas com altos índices de vulnerabilidade, apesar de conter setores com alto padrão de renda. As áreas vulneráveis abrangem $40,48 \mathrm{~km}^{2}$ do total de $283,41 \mathrm{~km}^{2}$, em sua maioria áreas da franja urbana, apresentando rendimento mensal baixo e pouca taxa de alfabetização da população residente, bem como reduzida oferta de equipamentos de cultura, lazer e educação.

A Figura 8 (zoneamento 2004 e zoneamento 2018) apresenta os zoneamentos dos planos de 2004 e o vigente de 2018, respectivamente. A partir da análise do zoneamento urbano, foi verificada a influência do plano de gestão do uso do solo no processo de desenvolvimento da área analisada. Foi constatado que a área está, majoritariamente, inserida em zonas de atividades mistas, econômica e periurbana, em ambos os planos de zoneamento. Ao comparar o plano de zoneamento de 2014 (vigente até 2018) com o novo plano aprovado no final de 2018 (em vigência), foi notado que o plano de 2004 previa zonas de atividade econômica (ZAE), centralidade (ZC), zona especial de preservação ambiental do sistema de espaços livres (ZEEL), zona especial de interesse social (ZEIS), zona mista (ZM), zona periurbana (ZP) e zona residencial (ZR). Por sua vez, o zoneamento vigente (ao final de 2018) excluiu a delimitação das ZEEL e ZEIS, com o objetivo de preservar os espaços livres, o ambiente natural e os usos ambientais e socioculturais. Todavia, essas zonas foram incorporadas às zonas ZM e ZR, aumentando a pressão de urbanização sobre áreas de conservação ambiental.
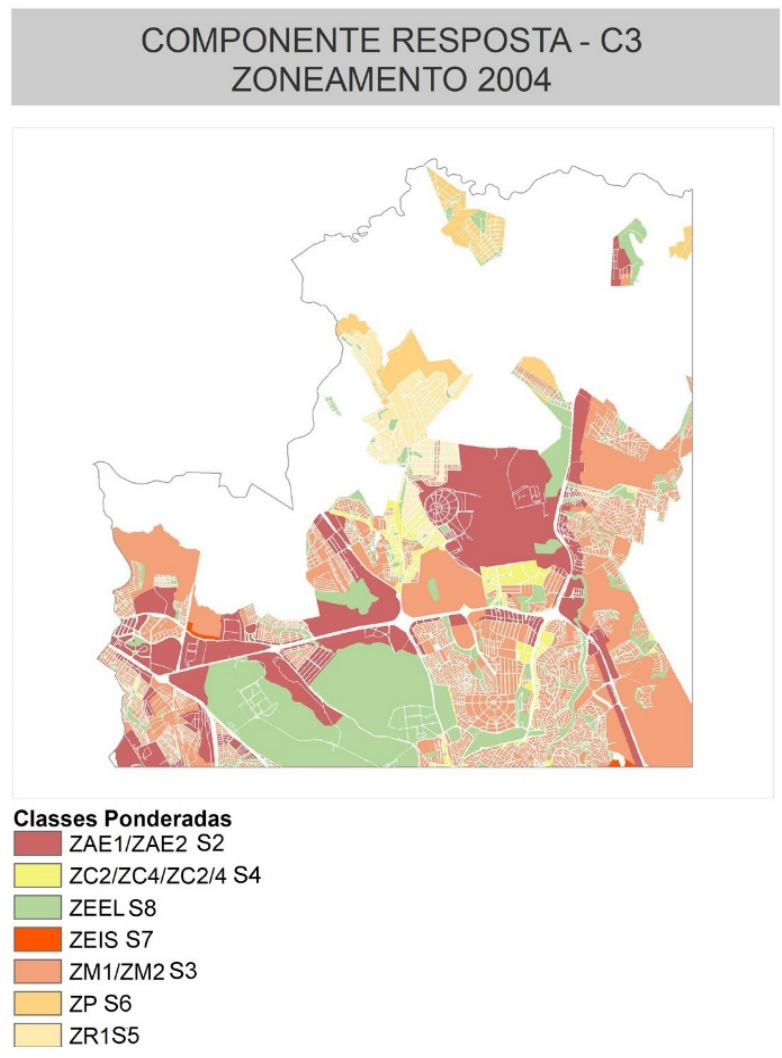

\section{COMPONENTE RESPOSTA - C3} ZONEAMENTO 2018

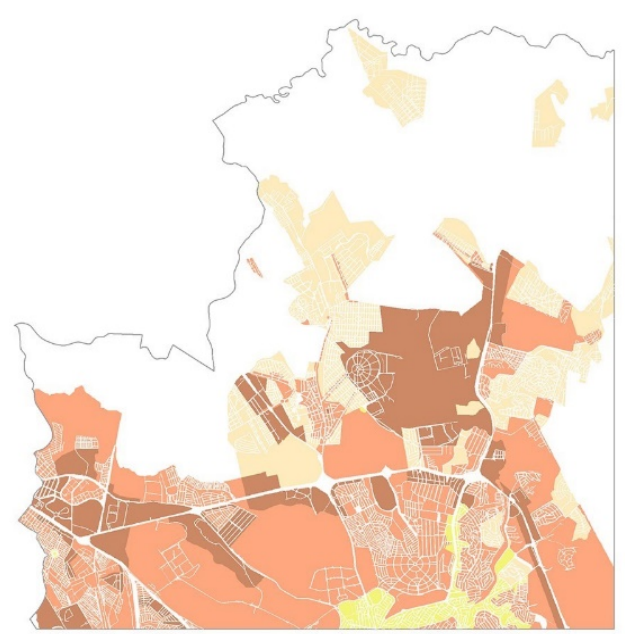

Classes Ponderadas

ZAE A/ZAE-C BG/ZAE B S2 ZC2/ZC4 S4

ZM1-A BG/ZM1-C BG/ZM2/ZM1-B BG/ZM1 S3

ZR-B BG/ZR/ZR-A BG S5

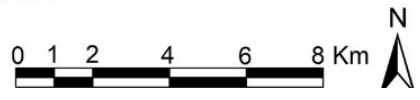

Figura 8 - Componente Resposta: zoneamentos de 2004 e de 2018. Fonte: Elaborada pelos autores.

As Figuras 9 e 10 apresentam, respectivamente, os valores de área e a distribuição espacial das categorias avaliadas pelo modelo PER para os zoneamentos de 2004 e 2018. 0 resultado gerado para o zoneamento de 2004 revelou que $48,9 \%$ da área analisada obteve nível de sustentabilidade classificado como ótimo e bom, 24,4\%, razoável, e 26,8\%, ruim. Por sua vez, pelo índice para o zoneamento de 2018, $29,7 \%$ da área analisada apresentou categoria de sustentabilidade classificado entre ótima e boa, sendo que $41,5 \%$ foram avaliados como razoáveis, e $28,7 \%$, como ruins.

Portanto, foram observadas mudanças decorrentes das alterações nas políticas de regulação do desenvolvimento urbano entre os planos de zoneamento de 2004 e 2018. Por consequência, a redução do 
percentual de áreas com nível ótimo e bom, associada ao aumento dos níveis razoável e ruim, indica prejuízos demasiados à sustentabilidade do desenvolvimento urbano ao comparar o efeito das mudanças de zoneamento entre os planos. Assim, é importante o acompanhamento futuro dos processos de desenvolvimento urbano, principalmente o monitoramento dos instrumentos de gestão do território, em razão da tendência de alteração apresentada nos primeiros meses de implementação do zoneamento de 2018.

Essa abordagem interdisciplinar pode ser observada no trabalho realizado por Silva et al. (2009), que propuseram um método de obtenção de índice de desenvolvimento sustentável a partir da integração de indicadores econômico, ambiental, social e pesquisa de opinião, assim como o emprego do método analítico AHP para análise de importância dos indicadores. 0 objetivo desses autores foi implementar uma ferramenta auxiliar para análise de políticas territoriais e de gestão aplicada ao desenvolvimento e crescimento sustentável. Seus resultados indicaram um índice de sustentabilidade aceitável para o município de Campina Grande-PB, mas destacaram áreas em condições de alerta. No presente estudo, foi obtido nível de sustentabilidade por dados indiretos (provenientes de órgãos de levantamento demográfico e da Prefeitura da cidade de Campinas-SP), que, apesar de não empregar informações sobre a percepção da população residente, permitiu a identificação e a espacialização das áreas e de seus diferentes níveis de sustentabilidade, destacando aquelas que requerem maior atenção por apresentar níveis entre razoável e ruim de desenvolvimento sustentável. Adicionalmente, o método apresentou sensibilidade para a identificação das principais alterações de sustentabilidade decorrentes da implementação de planos com mudanças da política de zoneamento urbano.

O modelo PER, aplicado no presente estudo, também foi utilizado por Macêdo \& Torres (2018) para a avaliação de indicadores ambientais do desenvolvimento do município de Brejo da Madre de Deus-PE. Esse autores se fundamentaram, predominantemente, no mapeamento de alteração da cobertura vegetal, empregando técnicas de sensoriamento remoto e incursões de campo. Os resultados apresentados pelos autores apontam que as ações de resposta oriundas dos órgãos públicos são importantes medidas reguladoras, mas, pelo estágio inicial de implementação, é prematuro afirmar que são suficientes para conter as pressões antrópicas sobre o ambiente. No presente estudo, a avaliação da sustentabilidade para área analisada no município de Campinas sugere que as alterações nas políticas de zoneamento, apesar de recentes, apresentaram potencial para alterar a sustentabilidade diante da pressão negativa sobre $o$ ambiente analisado. Todavia, é prematuro afirmar que essa situação tende a se agravar, por isso requer monitoramento frequente pelos órgãos gestores.

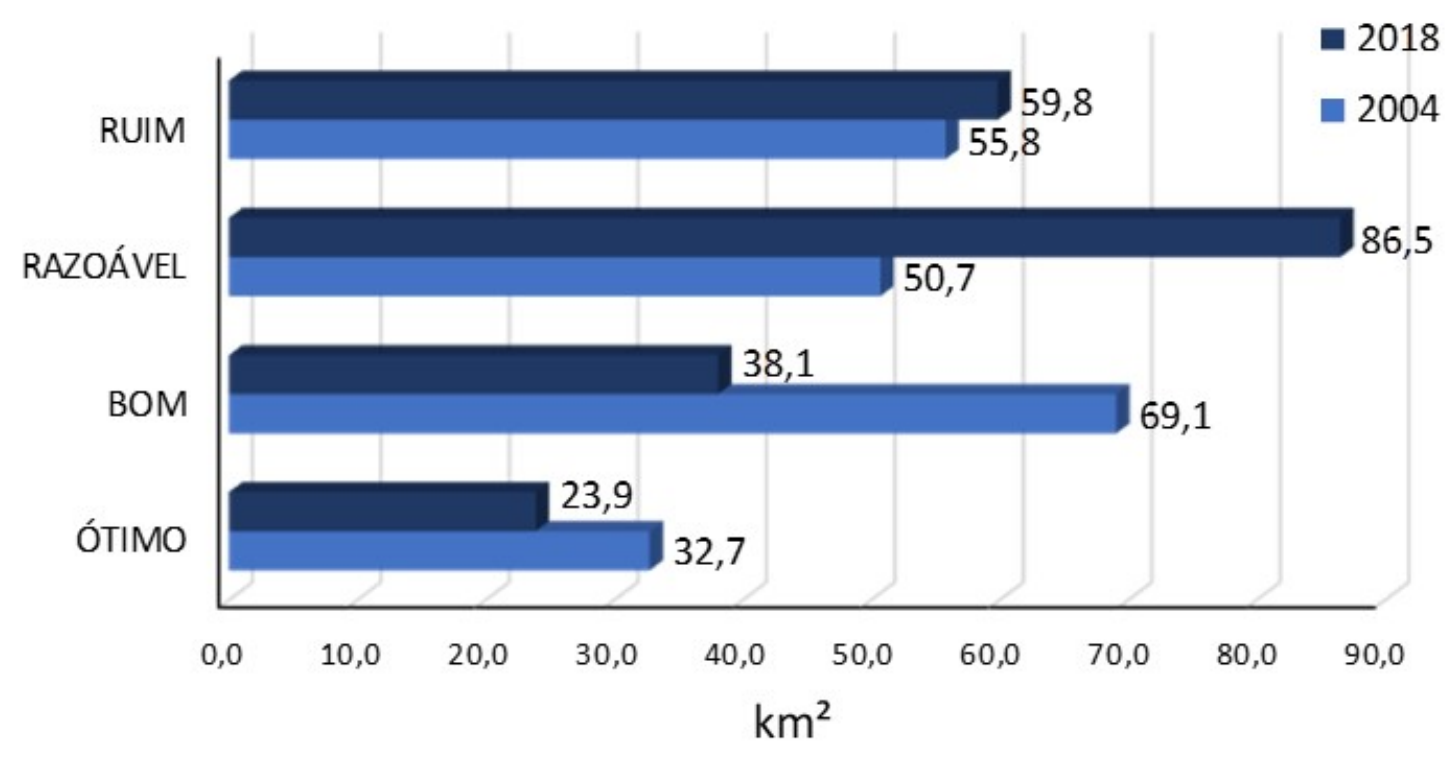

Figura 9 - Comparação entre os níveis de sustentabilidade urbana obtidos pelos zoneamentos de 2004 e de 2018. Fonte: Elaborada pelos autores. 
O trabalho realizado por Braga (2006) abordou a temática sustentabilidade e condições de vida em áreas urbanas, empregando como objeto de estudo duas regiões metropolitanas brasileiras. Nesse estudo, foi proposto um sistema de índices de sustentabilidade urbana (SISU), englobando índice ambiental, índice de capacidade político-institucional e índice de desenvolvimento humano municipal. Os resultados evidenciaram que o índice capacidade do sistema político-institucional foi capaz de avaliar a habilidade da sociedade em enfrentar os desafios da sustentabilidade urbana e oferecer respostas aos problemas relacionados, destacando-o como um bom indicador da gestão pública municipal. Dessa mesma forma, no presente estudo, há evidências da necessidade de avaliação das políticas de regulamentação e planejamento como meio de compreensão das alterações no processo de urbanização, corroborado pelos resultados obtidos na análise da sustentabilidade (zoneamentos de 2004 e 2018), que contribuíram para avaliar o efeito das ações de gestão pública voltadas ao desenvolvimento urbano, com a implementação e alteração da lei de zoneamento e uso e ocupação do solo.

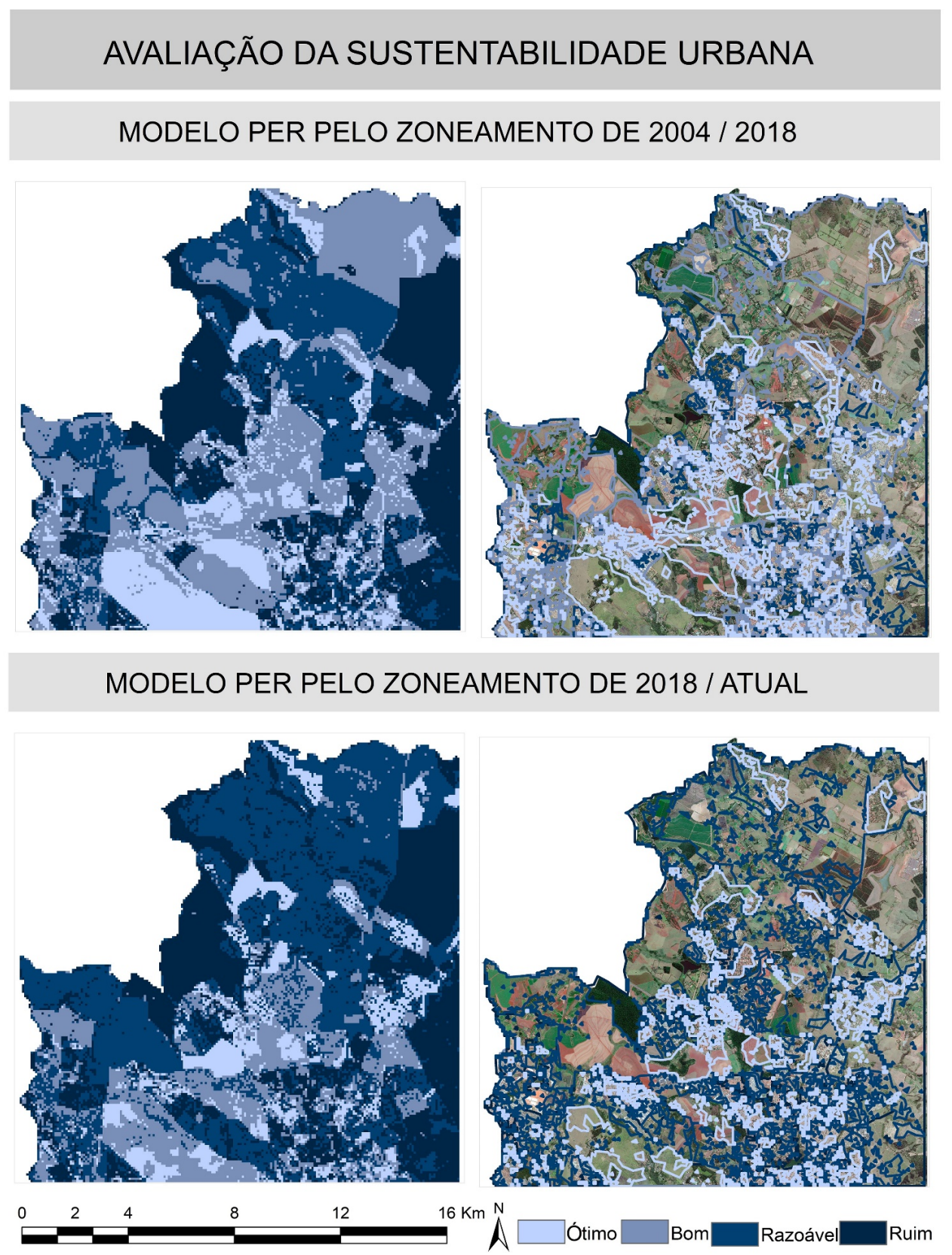

Figura 10 - Índices de sustentabilidade urbana obtidos pelos zoneamentos de 2004 e 2018. Fonte: Elaborada pelos autores. 
O método multicriterial CP foi aplicado como proposta de análise da prioridade de medidas de recuperação ambiental em áreas de preservação permanente (APP) da bacia hidrográfica do Ribeirão das Anhumas, municípios de Campinas e Paulínia-SP (Adami et al., 2013). De acordo com as observações dos autores, o método CP demonstrou habilidade para identificar áreas com diferentes cenários de prioridade quanto à demanda por medidas de recuperação. Ainda de acordo com esses autores, o método CP tende a ser adequado para dar suporte à identificação de áreas que requerem decisões urgentes, uma vez que concentrou $\sim 36 \%$ da área com prioridade alta e muito alta, $\sim 25 \%$ média e $\sim 39 \%$ baixa e muito baixa. Essa observação foi respaldada ao comparar o resultado do CP com o método CGT (Teoria dos Jogos Cooperativos, que maximiza a distância de algum ponto em relação ao nível mínimo, empregando a integração multiplicativa dos critérios). Na identificação de cenários de prioridade, o método CGT classificou pequena proporção de área $(\sim 8 \%)$ com prioridade alta e muito alta de recuperação, deixando $\sim 33 \%$ com média prioridade e $\sim 59 \%$ com baixa e muito baixa prioridade. Nesse estudo, ambos os métodos apresentaram potencial para classificação de prioridade de recuperação, porém diferenciaram quanto à área com urgência de tomada de decisão. No presente estudo, o método CP também foi eficiente na identificação de áreas com urgência para a tomada de decisão no que se refere à sustentabilidade do desenvolvimento urbano, com a implementação do plano de zoneamento de 2018, dada a identificação de $\sim 29 \%$ da área com sustentabilidade ruim. No entanto, não foram empregados outros métodos de integração que poderiam confirmar ou não os resultados da avaliação da sustentabilidade na área estudada. Por isso, são sugeridos estudos futuros que implementem diferentes métodos multicritérios de avaliação da sustentabilidade urbana. Cabe ainda ressaltar que o emprego do método CP foi considerado adequado por Baja et al. (2007) para a análise da aptidão do solo para uso agrícola. No estudo desses autores, os resultados obtidos a partir dos critérios índice de erosão, escoamento, acessibilidade e proximidade do curso d'água forneceram valores mais elevados de aptidão para usos com atividade agrícolas constatadas, assim validando a aplicação do método.

Adicionalmente, pela análise realizada no presente estudo e em concordância com o trabalho de Muñoz \& Anguita (2018) sobre a cidade de Madri, retratando a importância do estudo de mobilidade, é necessária em cidades bem planejadas a priorização do deslocamento sustentável como viés de acessibilidade, a partir de políticas de incentivo ao uso de transporte coletivo, da bicicleta e do caminhar, que também interferem na sustentabilidade urbana.

\section{Conclusões}

No presente estudo, a proposta de avaliação da sustentabilidade foi fundamentada no método CP e modelo PER, permitindo analisar a sustentabilidade urbana da região norte-noroeste de Campinas por categorias qualitativas. Ao empregar os indicadores para construção dos componentes Pressão, Estado e Resposta pelos zoneamentos de 2004 e 2018, foi possível demonstrar que a área estudada apresentou uma tendência de alteração da classificação de sustentabilidade entre os planos de zoneamento do município. Essa tendência evidenciou a ocorrência da pressão dos indicadores de urbanização com a alteração do plano de zoneamento, o que pode ser um agravante a longo prazo por ser um plano em fase de implementação e que, por isso, demanda monitoramento constante da sustentabilidade.

Também foi observada a ocorrência da expansão urbana no período de 1975 a 2018, acompanhada do crescimento populacional e redução da cobertura vegetal e da área rural. Essas alterações podem ter sido fatores que contribuíram para impactar a sustentabilidade do desenvolvimento da área estudada. Entretanto, a exclusão de zonas de preservação ambiental no plano de zoneamento 2018 expôs a área periurbana à intensificação da urbanização, tornando-se um fator relevante para a redução da sustentabilidade. São recomendadas, portanto, a fiscalização e a aplicação das leis de uso do solo urbano em futuras expansões para priorizar o desenvolvimento sustentável. Por fim, a área analisada de Campinas apresenta um potencial de crescimento urbano por não estar totalmente adensada, permitindo 
a intervenção de ações que possibilitem um desenvolvimento sustentável, integrando diversos fatores de melhoria da qualidade de vida, como é o caso da mobilidade urbana e conservação de áreas verdes.

\section{Referências}

Acselrad, H. (2001). A duração das cidades: sustentabilidade nas políticas urbanas. Rio de Janeiro: DP\&A.

Adami, S. F., Francisco, C. E. S., Coelho, R. M., \& Torres, R. B. (2013). Análise multicriterial aplicada à priorização para recuperação de áreas de preservação permanente: uma implantação em Sistemas de Informações Geográficas. Boletim Campineiro de Geografia, 2(3), 465-478.

Agência Nacional das Águas - ANA (2018). Base hidrográfica ortocodificada multiescalas de bacias do atlântico sul e sudeste. Recuperado em 12 de julho de 2018, de <http://metadados.ana.gov.br/geonetwork/srv/pt/main.home/

Baeninger, R. (2001). Região Metropolitana de Campinas: expansão e consolidação do urbano paulista. In D. J. Hogan, R. L. Carmo, M. P. Cunha, \& R. Baeninger (Eds.), Migração e ambiente nas aglomerações urbanas (pp. 321348). Campinas: Nepo/Unicamp.

Baja, S., Chapman, D. M., \& Dragovich, D. (2007). Spatial based compromisse programming for multiple criteria decision making in land-use planning. Environmental Modeling and Assessment, 12(3), 171-184. http://dx.doi.org/10.1007/s10666-006-9059-1.

Bana Costa, C. A. (2005). On the mathematical foundations of Macbeth. In J. Figueroa, S. Grecco, \& M. Ehrgott (Eds.), Multiple criteria decision analysis: state of art surveys (pp. 409-442). Boston: Springer Science, Business Media. http://dx.doi.org/10.1007/0-387-23081-5_10.

Batty, M. (2002). A decade of GIS: what next? Environment and Planning. B, Planning \& Design, 29(2), 127-158. http://dx.doi.org/10.1068/b2902ed.

Berg, A. G., \& Ostry, J. D. (2017). Inequality and unsustainable growth: two sides of the same coin? IMF Economic Review, 65(4), 792-815. http://dx.doi.org/10.1057/s41308-017-0030-8.

Berry, B. J. (1964). Approaches to Regional Analysis: a synthesis. Annals of the Association of American Geographers, 54(1), 2-11. http://dx.doi.org/10.1111/j.1467-8306.1964.tb00469.x.

Braga, T. M. (2006). Sustentabilidade e condições de vida em áreas urbanas: medidas e determinantes em duas regiões metropolitanas brasileiras. EURE. Revista Latinoamericana de Estudios Urbano Regionales, 32(96), 47-71.

Braga, T. M., Freitas, A. P. G., Duarte, G. S., \& Carepa-Sousa, J. (2009). Índices de sustentabilidade municipal: o desafio de mensurar. Nova Economia, 14(3), 11-33.

Campinas. (2014) Cobertura aerofotogrametrica do município de Campinas. Recuperado em 16 de fevereiro de 2018, de http://wms2.campinas.sp.gov.br/wmsmap/wms_ortofoto_2014.map

Campinas. Prefeitura Municipal. (2018). Projeto de lei de parcelamento, ocupação e uso do solo do município de Campinas. Recuperado em 10 de março de 2018, de https://zoneamento.campinas.sp.gov.br/

Congalton, R. G., \& Green, K. (2009). Assessing the accuracy of remotely sensed data: principles and practices (2nd ed.). New York: Lewis Publishers.

Chelleri, L. (2012). From the «Resilient City» to Urban Resilience. A review essay on understanding and integrating the resilience perspective for urban systems. Documents d'Analisi Geografica, 58(2), 287-306.

http://dx.doi.org/10.5565/rev/dag.175.

Environmental Systems Research Institute - ESRI. (2015). ArcGIS Desktop, Versão 10.4. Redlands: ESRI.

Franca, L. P. (2001). Indicadores ambientais urbanos (Manual Geo Cidades). Brasília: MMA/Consórcio Parceria 21.

Fritzsche, K., Schneiderbauer, S., Bubeck, P., Kienberger, S., Buth, M., Zebisch, M., \& Kahlenborn, W. (2014). The vulnerability sourcebook: concept and guidelines for standardised vulnerability assessments. Bonn: BMZ Bonn. 
Gaspar, J. (1996). 0 novo ordenamento do território: geografia e valores. In J. Gaspar (Ed.), Dinamismos sócioeconomicos e reorganização territorial: processos de urbanização e reestruturação produtiva (pp. 707-718). Coimbra: Instituto de Estudos Geográficos.

Gershon, M., \& Duckstein, L. (1983). Multiobjective approaches to river basin planning. Journal of Water Resources Planning and Management, 109(1), 13-28. http://dx.doi.org/10.1061/(ASCE)0733-9496(1983)109:1(13).

Gobbetti, L., \& Braba, B. (1997). Análise multiobjetivo. In R. L. L. Porto (Ed.), Técnicas quantitativas para o gerenciamento de recursos hídricos (pp. 361-418). Porto Alegre: ABRH, Editora da Universidade Federal do Rio Grande do Sul.

Goerl, R. F., Kobiyama, M., \& Pellerin, J. R. G. M. (2012). Proposta metodológica para mapeamento de áreas de risco a inundação: estudo de caso do município de Rio Negrinho-SC. Boletín Geográfico, 30(1), 81-100. http://dx.doi.org/10.4025/bolgeogr.v30i1.13519.

Herculano, S., Porto, M. F., \& Souza \& Freitas, C. M. (2000). Calidad de vida y riesgos ambientales. Niterói: EdUFF. Instituto Brasileiro de Geografia e Estatística - IBGE. (2011). Censo demográfico 2010. Rio de Janeiro: IBGE. Recuperado em 20 de agosto de 2018, de www.ibge.gov.br

Instituto Brasileiro de Geografia e Estatística - IBGE. (2015). Malhas territoriais 2015: malhas municipais, 2015. Recuperado em 7 fevereiro de 2018, de http://geoftp.ibge.gov.br/organizacao_do_territorio/malhas_territoriais/malhas_municipais/municipio_2015/

Kemerich, P. D. C., Ritter, L. G., \& Borba, W. F. (2014). Indicadores de sustentabilidade ambiental: métodos e aplicações. Revista Monografias Ambientais, 13(5), 3723-3736.

Köksalan, M., Wallenius, J., \& Zionts, S. (2013). An early history of multiple criteria decision making. Journal of Multi-Criteria Decision Analysis, 20(1-2), 87-94. http://dx.doi.org/10.1002/mcda.1481.

Kronemberger, D. M. P., Clevelario, J., Jr., Nascimento, J. A. S., Collares, J. E. R., \& Silva, L. C. D. (2008). Desenvolvimento sustentável no brasil: uma análise a partir da aplicação do barômetro da sustentabilidade. Revista Sociedade \& Natureza, 20(1), 25-50. http://dx.doi.org/10.1590/S1982-45132008000100002.

Lopes, A. F. A., \& Guerra, M. E. A. (2016). Uma análise dos instrumentos metodológicos que utilizam indicadores e índices para avaliar a sustentabilidade em ambientes urbanos. Revista Nacional de Gerenciamento de Cidades, 4(28), 1-14. http://dx.doi.org/10.17271/2318847242820161370.

Macêdo, H. C., \& Torres, M. F. A. (2018). Utilização do Modelo Pressão-Estado-Resposta na avaliação de indicadores ambientais do Municípios de Brejo da madre de Deus-PE. Revija za Geografijo, 35(5), 224-246.

Mahiny, A. S., \& Clarke, K. C. (2012). Guiding SLEUTH land-use/land-cover change modeling using multicriteria evaluation: towards dynamic sustainable land-use planning. Environment and Planning. B, Planning \& Design, 39(5), 925-944. http://dx.doi.org/10.1068/b37092.

Marques, A. P. (2017). Os caminhos sinuosos do desenvolvimento. Desenvolvimento e Sociedade, 2(2), 31-49.

Marques, M. L., Silva, M. C., \& Camargo, D. M. (2018). Análise espacial da vulnerabilidade socioambiental no município de Campinas. Revista Brasileira de Cartografia, 69(9), 1711-1723.

Martins, M. F., \& Cândido, G. A. (2013). Análise da sustentabilidade urbana no contexto das cidades: proposição de critérios e indicadores. In Anais do XXXVII Encontro Anual da ANPAD (pp. 1-16). Rio de Janeiro: ANPA.

Meneses, P. R., \& Almeida, T. D. (2012). Introdução ao processamento de imagens de sensoriamento remoto. Brasília: Universidade de Brasília.

Muñoz, J., \& Anguita, F. (2018). Los peajes urbanos como factor determinante de sostenibilidad y competitividad en el transporte urbano: un estudio aplicado a Madrid. EURE, 44(131), 53-74. http://dx.doi.org/10.4067/S025071612018000100053.

Nguyen, T. T., Verdoodt, A., Van Y, T., Delbecque, N., Tran, T. C., \& Van Ranst, E. (2015). Design of a GIS and multicriteria based land evaluation procedure for sustainable land-use planning at the regional level. Agriculture, Ecosystems \& Environment, 200, 1-11. http://dx.doi.org/10.1016/j.agee.2014.10.015. 
OpenStreetView. (2015). Recuperado em 20 de fevereiro de 2015, de https://openstreetview.org

Organization for Economic Cooperation and Development - OCDE (1993). Organization for economic cooperation and develop-ment: coreset of indicators for environmental performance reviews; a synthesis report by the group on the state of the environment. Paris: OCDE.

Programa das Nações Unidas para o Desenvolvimento - PNUD. (2011). Relatório do Desenvolvimento Humano de 2011: sustentabilidade e equidade: um futuro melhor para todos. New York: PNUD.

Programa das Nações Unidas para o Desenvolvimento - PNUD. (2013). Ranking IDHM municípios 2010. Brasília: PNUD.

Programa das Nações Unidas para o Meio Ambiente - PNUMA. (2017). Projeto Geo Cidades: relatório ambiental urbano integrado. Rio de Janeiro: PNUMA/MMA/IBAM/ISER/REDEH.

Santos, J. O. (2015). Relações entre fragilidade ambiental e vulnerabilidade social na susceptibilidade aos riscos. Mercator, 14(2), 75-90. http://dx.doi.org/10.4215/RM2015.1402.0005.

Sepe, P. M., \& Braga, R. (2009). Indicadores de sustentabilidade e o planejamento urbano-ambiental: uma contribuição para a aplicação na cidade de São Paulo. In Anais do IX Seminário de Pós-Graduação em Geografia da Unesp Rio Claro (pp. 225-240). Rio Claro: UNESP.

Silva, A. M., Correia, A. M. M., \& Cândido, G. A. (2010). Ecological footprint method: avaliação da sustentabilidade no município de João Pessoa, PB. In G. A. Cândido (Ed.), Desenvolvimento sustentável e sistemas de indicadores de sustentabilidade: formas de aplicações em contextos geográficos diversos e contingências específicas (pp. 236-271). Campina Grande: UFCG.

Silva, M. G., Cândido, G. A., \& Martins, M. D. F. (2009). Método de construção do índice de desenvolvimento local sustentável: uma proposta metodológica e aplicada. Revista Brasileira de Produtos Agroindustriais, 11(1), 55-72. http://dx.doi.org/10.15871/1517-8595/rbpa.v11n1p55-72.

Valeriano, M. M., \& Rossetti, D. F. (2012). Topodata: brazilian full coverage refinement of SRTM data. Applied Geography, 32(2), 300-309. http://dx.doi.org/10.1016/j.apgeog.2011.05.004.

Van Maarseveen, M., Martinez, J., \& Flacke, J. (2019). GIS in sustainable urban planning and management: a global perspective. CRC Press.

Wang, S., Sun, C., Li, X., \& Zou, W. (2016). Sustainable development in china's coastal area: based on the driverpressure-state-welfare-response framework and the data envelopment analysis model. Sustainability, 8(9), 958. http://dx.doi.org/10.3390/su8090958.

$\mathrm{Wu}, \mathrm{J}$. (2014). Urban ecology and sustainability: the state-of-the-science and future directions. Landscape and Urban Planning, 125, 209-221. http://dx.doi.org/10.1016/j.landurbplan.2014.01.018.

Zeleny, M., \& Cochrane, J. L. (1982). Multiple criteria decision making. New York: McGraw-Hill Book Company.

Zuffo, A. C., Reis, L. F. R., Santos, R. D., \& Chaudhry, F. H. (2002). Aplicação de métodos multicriteriais ao planejamento de recursos hídricos. Revista Brasileira de Recursos Hídricos, 7(1), 81-102. http://dx.doi.org/10.21168/rbrh.v7n1.p81-102.

Editor: Harry Bollmann

Recebido: Jul. 13, 2019

Aprovado: Ago. 10, 2020 